\title{
White Central American
}

National Cancer Institute

\section{Source}

National Cancer Institute. White Central American. NCI Thesaurus. Code C128993.

A person having origins in the any of the countries of Central America who identifies as white. 